\title{
Síndrome da Cefaléia Cervicogênica
}

Deusvenir de Souza Carvalho ${ }^{1}$

\section{RESUMO}

O conceito de cefaléia cervicogênica foi introduzido por Sjaastad et al. em 1983. Mesmo permanecendo como uma síndrome controversa, critérios diagnósticos e seus refinamentos foram publicados em 1990 e 1998 . Apresentamos uma breve revisão dessa síndrome, enfocando seus aspectos anatômicos, fisiopatológicos e de tratamento.

Unitermos: Coluna cervical, cefaléia, bloqueio anestésico de nervo.

\section{Introdução}

Nas condições normais, a coluna cervical é orientada verticalmente no plano frontal e mostra uma discreta convexidade anterior ${ }^{1}$. O crânio é conectado à coluna pelas superfícies articulares dos côndilos do occipital e das superfícies articulares do atlas. A posição da cabeça é mantida por numerosos músculos localizados anterior e posteriormente em relação à coluna. Músculos anteriores podem conectar indiretamente a mandíbula com o esterno e a clavícula por inserção no osso hióide. O baricentro do crânio é localizado aproximadamente na sela túrcica, sendo, com isso, anterior aos côndilos do occipital $^{2}$. A força de gravidade é contrabalaçada posteriormente pelos músculos da nuca que são mais potentes (Figura 1). Uma freqüente causa de alteração na postura da cabeça e do pescoço é a falha nos músculos posteriores. A curvatura normal é perdida ou invertida. Com o tempo ocorre degeneração artrótica. O estresse pode levar à contratura muscular e à alteração funcional. A relativa distorção do hióide pode resultar em alteração da postura da mandíbula.

O mau alinhamento dos ombros também é uma alteração freqüente. Pode ser por diferença no comprimento das pernas e conseqüente desalinhamento da coluna. Eventualmente, os causadores são os maus hábitos posturais. A necessidade de manter a linha

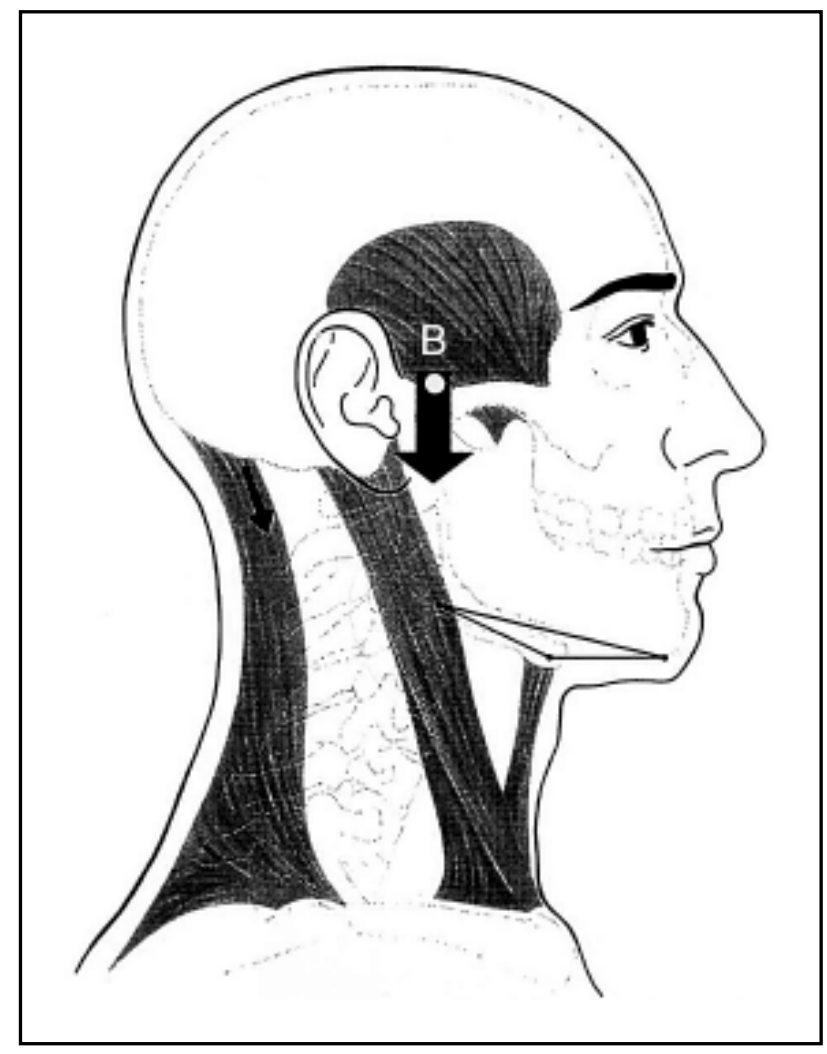

Figura 10 centro de gravidade do crânio é anterior ao apoio ósseo da coluna (seta maior). A musculatura posterior mantém a postura (seta menor) (adaptação da figura de Mongini $F^{1}$, pág. 54).

\footnotetext{
Professor-adjunto e Chefe do Setor de Investigação e Tratamento das Cefaléias (SITC) da Disciplina de Neurologia da Escola Paulista de Medicina - Unifesp.
} 
bipupilar horizontal leva ao desvio do pescoço e dos ombros. Tal situação provoca maior esforço dos músculos cervicais, particularmente do esternocleidomastóideo e do trapézio.

Alterações da curvatura das vértebras superpõem-se à má postura dos ombros. A constante mudança da atividade e o estiramento muscular, bem como da orientação corporal, levam à sobrecarga e ao aparecimento de pontos dolorosos e sensação de aperto. Esses pontos dolorosos podem diferenciar a cefaléia cervicogênica primária da enxaqueca e da cefaléia tipo tensão ${ }^{3}$.

A busca de quadros de cervicalgia secundária a diversas patologias provenientes das desordens craniomandibulares e temporomandibulares é antiga.

Os traumatismos de coluna (whiplash) são freqüentes atualmente e têm sido implicados na gênese de cefaléia em grande contingente de pacientes.

O termo cefaléia cervicogênica foi introduzido por Sjaastad et al. ${ }^{4}$ em 1983 como uma hipótese.

\section{Fisiopatogenia}

A Classificação e os Critérios Diagnósticos das Cefaléias, Nevralgias Cranianas e Dor Facial, proposta em 1988 pelo Comitê de Classificação das Cefaléias da Sociedade Internacional de Cefaléia (IHS) contempla quadro de dor cervical, secundária, no item 11.2.1, coluna cervical, e, no 11.2.2, tendinite retrofaríngea. A expressão sintomatológica dessa controversa síndrome, a cefaléia cervicogênica, ainda não permite ser estabelecida como quadro primário ou secundário. Ainda faltam investigações mais precisas que permitam verificar os supostos aspectos centrais da síndrome. Há várias evidências de que anormalidades nas estruturas somáticas e viscerais da região cervical podem ser sede de dor referida ao crânio e à face ${ }^{6}$ (Figura 2). A estimulação do componente sensitivo de $\mathrm{C} 1$ acarreta dor orbitofrontal e no vértex. A irritação de $\mathrm{C} 2$ e a estimulação dos nervos occipitais geram dor na porção posterior do segmento cefálico. A dor unilateral ipsilateral da cabeça e do braço sem desvio ao repouso indica uma doença orgânica. A redução do grau de movimento no pescoço é típica, mas não especifica síndrome de cefaléia cervicogênica.

\section{Quadro clínico e critérios diagnósticos}

Essa controversa síndrome de cefaléia cervicogênica foi hipotetizada em $1983^{4}$, e os critérios diagnósticos foram estabelecidos em 1990 e revisados em $1998^{7,8}$. Os critérios diagnósticos da síndrome de cefaléia cervicogênica são apresentados a seguir:

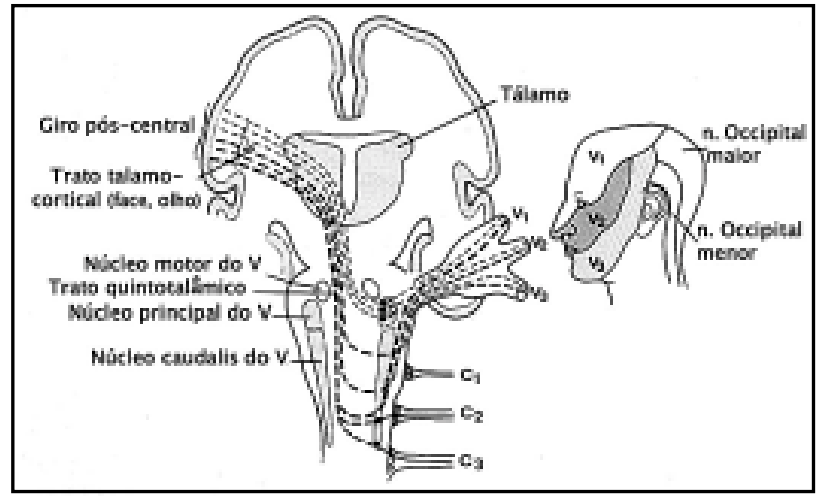

Figura 2 A aferência comum das raízes cervicais e do nervo trigêmeo. Compressão de raízes cervicais pode provocar dor no território do nervo trigêmeo (adaptação da figura de Jansen $J$ et al. ${ }^{6}$, pág. 14).

\section{Sinais e sintomas maiores}

I- Sintomas e sinais de envolvimento cervical:

a) precipitação da dor cervical semelhante à espontânea por:

1. movimento do pescoço ou sustentação desajeitada da cabeça;

2. pressão externa da região cervical posterior e superior ipsilateral ou da região occipital;

b) redução da movimentação cervical habitual;

c) dor na mão, ombro e pescoço ipsilateral, de natureza vaga e não-radicular, ou ocasionalmente dor no braço de natureza radicular.

II- Alívio completo ou quase completo (> 90\%) da dor após o bloqueio anestésico do nervo grande occipital e/ou da raiz $\mathrm{C} 2$ no lado sintomático.

III- Unilateralidade da dor sem mudança de lado, podendo ocorrer o quadro em qualquer um dos lados.

IV- Características da dor:

a) moderada, não-excruciante, geralmente de natureza não-pulsátil, começando no pescoço e espalhando-se para as áreas oculofrontotemporal, onde, em geral, é máxima;

b) duração variável (horas) ou dor contínua flutuante;

V- Outras características de alguma importância:

a) melhora eventual com tratamento preventivo com indometacina;

b) melhora eventual da crise com uso de ergotamina ou de sumatriptano;

c) preponderância no sexo feminino;

d) história de trauma craniano ou cervical (whiplash).

VI- Características de pouca importância:

a) náusea;

b) fonofobia e fotofobia; 
c) vertigens;

d) alteração visual ipsilateral;

e) dificuldades de deglutição;

f) edema e hiperemia na área periocular ipsilateral.

\section{Tratamento}

Os pacientes com síndrome de cefaléia cervicogênica trazem um desafio, tanto para o estabelecimento de um diagnóstico preciso como para orientar os possíveis tratamentos. Muitas vezes há dificuldade em diferenciá-la da enxaqueca sem aura e da cefaléia tipo tensão, as quais são tratadas com esquemas que não beneficiam a cefaléia cervicogênica.

Uma vez preenchidos os critérios do diagnóstico, diversos tratamentos para a síndrome de cefaléia cervicogênica têm sido propostos, com predomínio de intervenções invasivas, tais como estimulação transcutânea, anestesia local repetida, descompressão, secção e/ou avulsão do nervo grande occipital e do nervo occipital menor, bem como de raízes e gânglios cervicais, estabilização e/ou fusões vertebrais, radiofreqüência de discos intervertebrais e de nervos cervicais e estimulação epidural. Esses tratamentos invasivos tentam diminuir a aferência periférica dos impulsos dolorosos. A aplicação de toxina botulínica pode trazer alívio ao paciente por tempo limitado, porém pode agravar os distúrbios posturais (experiência do autor, em um caso tratado).

Como propostas não-invasivas têm-se a fisioterapia e o uso de antiinflamatórios não-hormonais (AINH) ${ }^{9}$.

A fisioterapia pode melhorar os hábitos posturais, amplificar e adequar os movimentos. Quanto à dor, se houver benefício, em geral é pequeno e por tempo limitado?.

O paracetamol pode trazer alívio temporário para a dor leve ${ }^{9}$.

Os AINH podem beneficiar alguns pacientes, em geral, particularmente a indometacina em doses elevadas (de $100 \mathrm{mg} / \mathrm{dia}$ a $200 \mathrm{mg} / \mathrm{dia})^{10}$. Quando ocorre intolerância gástrica por essas drogas, os inibidores da COX-2, como o rofecoxib, podem ser usados.

Os aspectos psicológicos, em sua avaliação fenomenológica, podem evidenciar distúrbios de ansiedade e depressão, que, sendo abordados e orientados, trazem benefício ${ }^{11}$.

Ainda faltam investigações mais precisas que permitam verificar os aspectos centrais dessa síndrome, principalmente o neuroquímico, o que levaria a novas propostas de tratamento clínico.

\section{SUMMARY}

\section{Cervicogenic headache}

The term cervicogenic headache was introduced by Sjaastad and coworkers in 1983. Although a controversial syndrome, diagnostic criteria and refinements of these criteria were published in 1990 and 1998. Herein we present a brief overview of this syndrome and its anatomic, pathophysiologic and treatment aspects.

\section{Keyw ords}

Cervical spine, headache, diagnostic nerve block.

\section{Referências}

1. Mongini F. Headache and facial pain. Stuttgart, Thieme, 1999, pp. 51-62.

2. Rocabado M. Biomechanical relationship of the cranial, cervical, and hyoid regions. Cranio, 1:61-6, 1983.

3. Bansevicius D, Pareja JA. The skin roll test: a diagnostic test for cervicogenic headache. Funct Neurol, 13 (2):125-33, 1998.

4. Sjaastad O, Saunte C, Hovdal H, Breivik H, Gronbaek E. Cervicogenic headache: an hypothesis. Cephalagia, 3:249-56, 1983

5. IHS. International Headache Society. Headache Classification Commitee. Classification and diagnostic criteria for headache disorders, cranial neuralgias and facial pain. Cephalalgia, 8:suppl. 7:1-96, 1988.

6. Jansen J, Markakis E, Rama B, Hildebrandt J. Hemicranial attacks on permanent hemicrania - a seque of upper cervical root compression. Cephalalgia, 9:123-30, 1989

7. Sjaastad O, Fredriksen, TA, Pfaffenrath V. Cervicogenic headache: diagnostic criteria. Headache, 30:725-6, 1990.

8. Sjaastad O, Fredriksen TA, Pfaffenrath V. Cervicogenic headache: diagnostic criteria. The cervicogenic headache international study group. Headache, 38:442-5, 1998.

9. Sjaastad O, Fredriksen TA, Stolt-Nielsen A, Salvesen R, Pareja JA, Poughias L, Kruszewwski P, Inan L. Cervicogenic headache: a clinical review with special emphasis on therapy. Funct Neurol, 12:305-17, 1997.

10. De Souza Carvalho D, Carramate JFP, Teixeira DS, Araujo MG, Zukerman E. Síndrome de cefaléia cervicogênica responsiva a indometacina. Migrâneas e Cefaléias, 2:111, 1999

11. Missiano ECM, de Sousa Carvalho D. Avaliação psicológica da síndrome de cefaléia cervicogênica. XIV Congresso da Sociedade Brasileira de Cefaléia, 1-3 de junho, 2000, São Paulo (Tema livre apresentado).

\footnotetext{
Endereço para correspondência:

Deusvenir de Souza Carvalho

Rua Pedro de Toledo, 980, conjunto 33

CEP 04039-002 - São Paulo, SP

Fone/Fax: (0xx11) 5574-6843

E-mail: deusveni@provida.org.br
} 